\title{
VATS biopsy of an adult with pulmonary langerhans cell histiocytosis: case report
}

\author{
Kathy Jane S. Tripole ${ }^{1}$, Jose Luis J. Danguilan ${ }^{2}$, Jaime M. Mendoza ${ }^{1}$, Rex Michael C. Santiago ${ }^{3}$ \\ ${ }^{1}$ Department of Pulmonary, Critical Care and Sleep Medicine, ${ }^{2}$ Department of Thoracic Surgery and Anesthesia, ${ }^{3}$ Department of Pathology and \\ Laboratory, Lung Center of the Philippines, Quezon City, Philippines \\ Correspondence to: Dr. Kathy Jane S. Tripole. Lung Center of the Philippines, 17 Mahiyain St., Quezon City, Philippines. \\ Email: kathyjanestripole@gmail.com.
}

\begin{abstract}
A 29-year-old Filipino male smoker presented with dyspnea and a right-sided pneumothorax with subsequent chest tube drainage. Chest CT scan revealed multiple diffuse and mostly interconnected thin and thick-walled cystic structures of varying sizes and shapes with most located in both upper lobes. Video-assisted thoracoscopic surgery (VATS) wedge resection of the right lower lobe posterobasal segment and mechanical pleural abrasion were done. Intraoperatively, there were multiple bullae and diffuse small cysts interspersed with normal lung tissue. Histopathology and immunohistochemistry findings revealed pulmonary Langerhans cell histiocytosis (PLCH). Smoking has been hypothesized to induce a clonal proliferative, neoplastic process or a reactive immune activity in PLCH. The patient was advised smoking cessation and is on close follow-up. He is doing well 10 months after hospital discharge. PLCH is a very rare disease and diagnosis was obtained by VATS. To the authors' knowledge, this is also the first fully documented case of PCLH in the Philippines.
\end{abstract}

Keywords: Pulmonary Langerhans cell histiocytosis; histiocytosis X; cystic lung disease; case report

Received: 20 April 2020; Accepted: 28 June 2020; Published: 20 April 2021.

doi: 10.21037 /jovs-2020-02

View this article at: http://dx.doi.org/10.21037/jovs-2020-02

\section{Introduction}

Langerhans cell histiocytosis ( $\mathrm{LCH})$ is a disease involving proliferation of Langerhans cells. It was previously named Histiocytosis $\mathrm{X}$ due to the unknown cellular basis of the involved cell. It is a rare disease occurring $0.5-5.4$ cases per million persons per year (1). It commonly presents during the 2nd-4th decades of life and has no gender predilection. It is sporadic and as many as $90 \%$ of patients are smokers or have significant exposure to smoking (2). The disease can be stratified as single system $\mathrm{LCH}$ involving the endocrine and nervous system, lymph nodes, bones, skin or like in this patient, the lungs, and the multisystem $\mathrm{LCH}$, which is classified as with or without involvement of risk organs like the bone marrow, liver spleen and central nervous system (3). This patient is a single system LCH involving the lungs based on clinical, radiographic and histopathologic findings. Minimally invasive thoracic surgery was not only diagnostic but also therapeutic because mechanical pleurodesis was done with no further recurrence of the pneumothorax. We present the following case in accordance with the CARE reporting checklist (available at https://jovs.amegroups. com/article/view/10.21037/jovs-2020-02/rc).

\section{Case presentation}

A 29-year-old male had sudden onset of dyspnea and right back pain. There was no associated cough, fever, weight loss or any other symptom. He had no comorbid condition. He was a 2.5 pack year smoker and an occasional alcoholic beverage drinker. His past medical history is unremarkable. There was no similar illness in immediate family members. He was brought to a local hospital and chest radiograph revealed a right-sided pneumothorax. He underwent tube thoracostomy which afforded relief of symptoms; the chest tube was removed a few days later. On admission, 


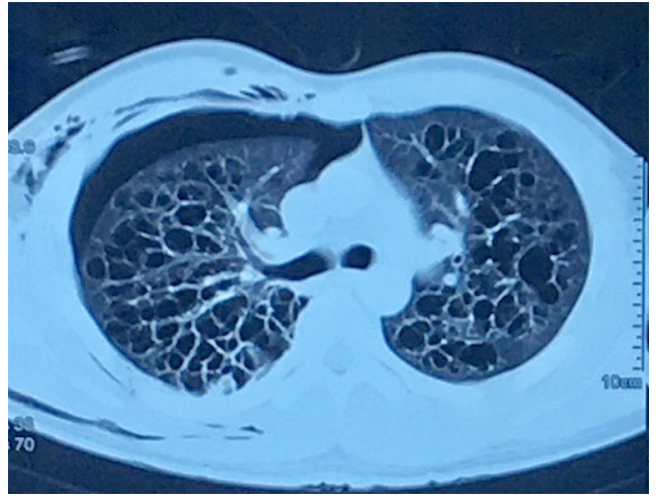

Figure 1 Chest CT scan showing multiple thin and thick-walled cystic structures.

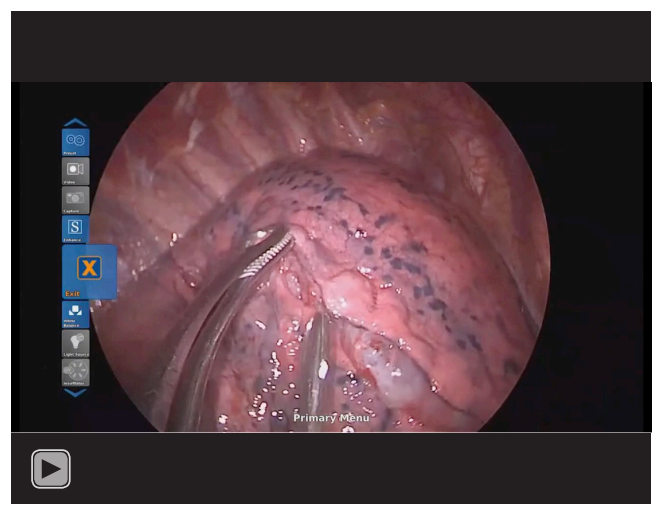

Video 1 The video shows a wedge resection of a representative portion of the diseased lung followed by mechanical pleural abrasion which led to the diagnosis of this unusual disease entity.

he was asymptomatic. The interval from the initial tube thoracostomy performed in another hospital to admission in our hospital was 2 weeks. Chest CT scan showed multiple thin and thick walled cystic structures of varying sizes and shapes, mostly interconnected, with majority located in both upper lobes (Figure 1). The consideration was a multi-cystic lung disease and differential diagnoses included pulmonary Langerhans cell histiocytosis (PLCH), pulmonary tuberculosis, bronchiectasis, and diffuse pulmonary emphysema-bronchiectasis.

The patient was managed as a case of diffuse cystic lung disease. Diagnostic tests included spirometry showing moderately severe obstructive and probable restrictive ventilatory defects without significant response to bronchodilator, arterial blood gas determination revealing normal acid-base balance and adequate oxygenation,

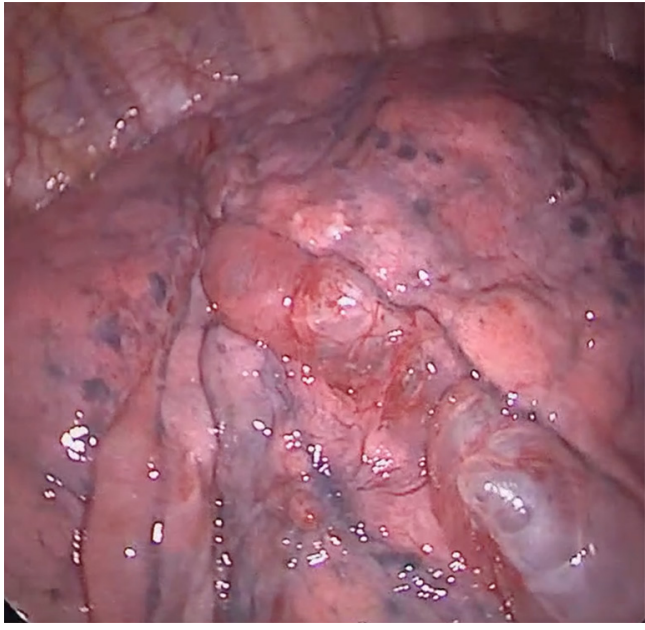

Figure 2 Thoracoscopic view showing multiple bullae and diffuse small cysts.

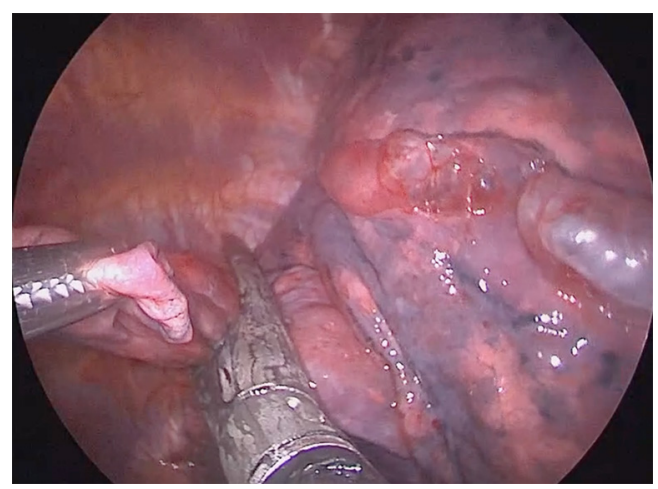

Figure 3 Wedge resection biopsy of the posterobasal segment of the right lower lobe.

ECG with sinus rhythm, and 2D echo showing absence of pulmonary hypertension. Blood count, renal and liver function test, lipid profile, fasting blood sugar, ESR, and urinalysis were unremarkable. Workup for tuberculosis such as sputum smear microscopy, sputum geneXpert and purified protein derivative were negative.

He underwent uniportal video-assisted thoracoscopic surgery (VATS) (Video 1). Intraoperatively, multiple bullae of varying sizes approximately $2 \mathrm{~cm}$ on the right upper lobe and diffuse small cysts interspersed with normal lung tissue were found (Figure 2). Wedge resection of the right lower lobe posterobasal segment was done (Figure 3) followed by mechanical abrasion of the parietal pleura (Figure 4). The resected specimen consisted of a $5 \mathrm{~cm} \times 3 \mathrm{~cm} \times 1.7 \mathrm{~cm}$ wedge-shaped lung tissue weighing 6 gms. with smooth 


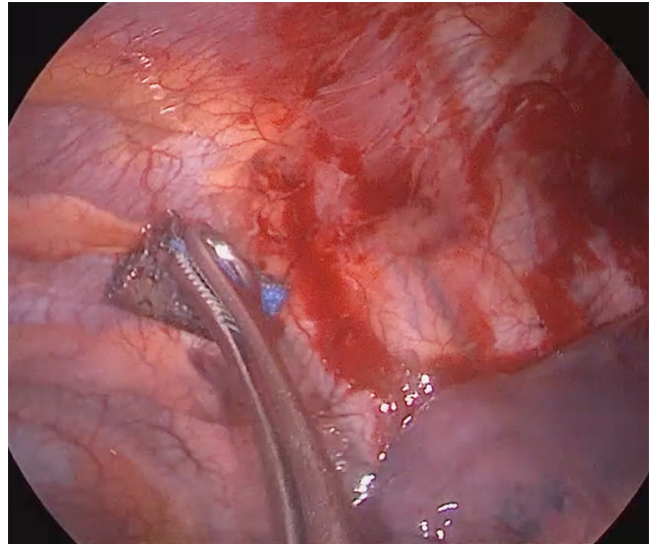

Figure 4 Mechanical abrasion of the parietal pleura.

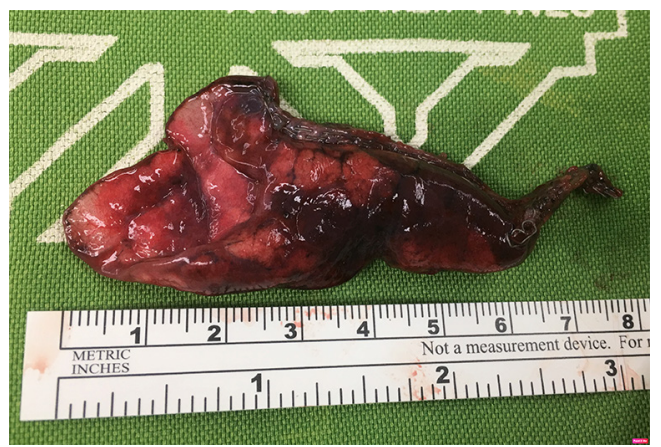

Figure 5 Gross specimen of wedge-shaped lung tissue.

gray/brown pleura, and few parenchymal cystic spaces, with sections of uninvolved lung tissues that are tan/brown and subcrepitant to touch (Figure 5).

Microscopic section showed moderate to severe chronic interstitial inflammation associated with aggregates of atypical cells and some cysts, predominantly in peribronchiolar/perilobular distribution. The atypical cells had ovoid, pale nuclei, occasional conspicuous nucleoli, irregular nuclear membranes, and ample eosinophilic cytoplasm (Figure 6). By immunohistochemistry, these cells were diffusely and strongly positive for $\mathrm{S} 100$ and CD1a, negative for CK, TTF1, CD3, CD20, CD68, and calretinin, which were all compatible with PLCH (Figure 7).

The patient was discharged without complications. He was advised to stop smoking with regular follow-up for monitoring of disease progression by chest imaging and is doing well 10 months after discharge from the hospital. He has also stopped smoking completely because he does not want his condition to worsen. All procedures performed

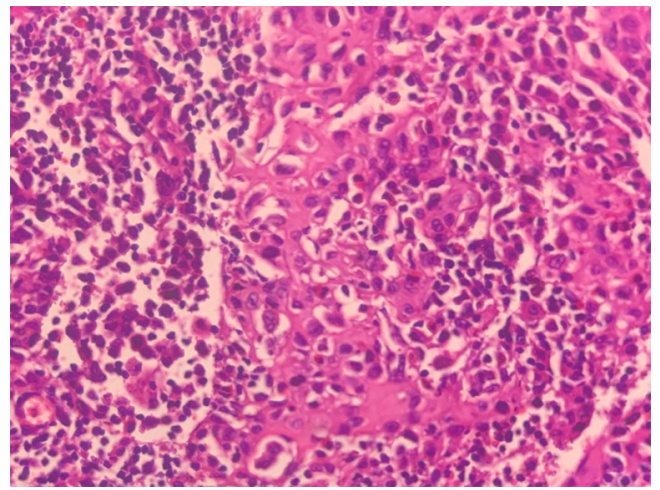

Figure 6 Atypical cells with irregular nuclei and eosinophilic cytoplasm (Hematoxylin and Eosin stain, 400× magnification).

in study involving human participants were in accordance with the ethical standards of the institutional and national research committees and with the Helsinki Declaration (as revised in 2013). Written informed consent was obtained from the patient for publication of this manuscript and any accompanying images.

\section{Discussion}

Diffuse cystic lung diseases are a diverse group of lung disorders characterized by the presence of multiple regular or irregular spherical parenchymal lucencies bordered by a thin wall and having a well-defined interface with normal lung (4). PLCH predominantly affects young adults between the ages of 20 to 40 years almost exclusively in smokers with no gender predilection (2). Tobacco smoke has been implicated in the pathogenesis of PCLH but how it triggers the formation of its lesions is not clear. It has been suggested that there is an immune response to a component of tobacco smoke but proliferation of blood lymphocytes from patients with PLCH in response to tobacco glycoprotein was found to be decreased compared with controls (5).

The clinical presentation of PLCH is variable but mainly respiratory. This patient presented with spontaneous pneumothorax which is more common in young males (6). A standard chest radiograph can lead to the diagnosis of adult PLCH in a most patients with abnormalities varying from reticulomicronodular infiltration to cysts within the infiltrates in both lungs (7). HRCT is mandatory when PCLH is suspected and provides additional details such as cavitation of nodules, which is not readily visible on standard radiographs (8). The definitive diagnosis rests on the 


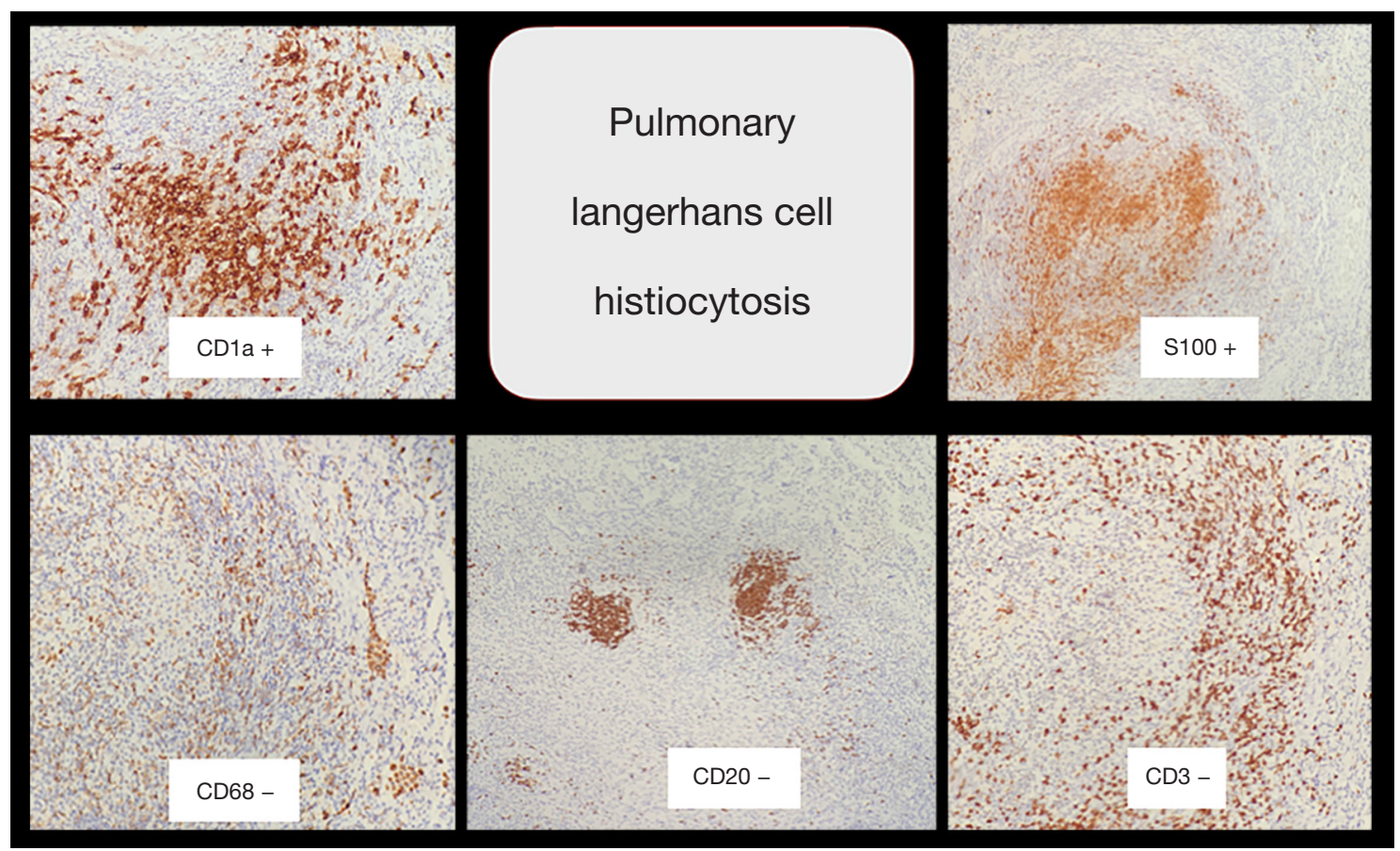

Figure 7 Immunohistochemistry compatible with pulmonary Langerhans cell histiocytosis. Immunohistochemistry staining CD1a (400x), CD68 (200x), CD20 (40x), S100 (200x), CD3 (200x).

identification of a Langerhans cell granuloma with tissues obtained by surgical biopsy, usually VATS. Pulmonary function abnormalities are variable and depend on the predominant anatomical lesions and disease duration (6).

Accumulation of activated Langerhans cells organized into loose granulomas that develop and destroy the distal bronchiole walls is the pathological hallmark of PLCH, associated with lymphocytes and inflammatory cells, including eosinophils and macrophages (9).

The natural history of the disease is variable and unpredictable in the individual patient with around $50 \%$ having a favorable outcome, spontaneously or with steroid therapy (6). Therefore, long-term follow-up is mandatory and may detect exacerbation of respiratory dysfunction after many years, or, rarely, a relapse with recurrent nodule formation (10).

Since many patients with PLCH recover spontaneously or remain in a stable condition without treatment, the effectiveness of various treatment modalities is difficult to assess; the rarity of PLCH also precludes recruitment of patients for controlled therapeutic trials (9).

The association between PLCH and smoking suggests a causal role for cigarette smoke. Therefore, smoking cessation is mandatory. Resolution of the disease after smoking cessation has been reported (11).

\section{Conclusions}

PLCH is an unusual disease entity with a strong association with cigarette smoking. The diagnosis lies on a combined assessment of clinical, radiographic and histopathologic aspects. VATS plays an important role in obtaining adequate tissue samples for histopathological diagnosis. Optimal management requires a multidisciplinary approach and a cooperative patient. Smoking cessation is still the cornerstone of prevention and treatment.

\section{Acknowledgments}

Funding: None.

\section{Footnote}

Reporting Checklist: The authors have completed the CARE reporting checklist. Available at https://jovs.amegroups. com/article/view/10.21037/jovs-2020-02/rc

Conflicts of Interest: All authors have completed the 
ICMJE uniform disclosure form (available at https://jovs. amegroups.com/article/view/10.21037/jovs-2020-02/coif). JLJD serves as an unpaid editorial board member of fournal of Visualized Surgery from June 2019 to May 2021. The other authors have no conflicts of interest to declare.

Ethical Statement: The authors are accountable for all aspects of the work in ensuring that questions related to the accuracy or integrity of any part of the work are appropriately investigated and resolved. All procedures performed in this study were in accordance with the ethical standards of the institutional and national research committees and with the Helsinki Declaration (as revised in 2013). Written informed consent was obtained from the patient for publication of this manuscript and any accompanying images.

Open Access Statement: This is an Open Access article distributed in accordance with the Creative Commons Attribution-NonCommercial-NoDerivs 4.0 International License (CC BY-NC-ND 4.0), which permits the noncommercial replication and distribution of the article with the strict proviso that no changes or edits are made and the original work is properly cited (including links to both the formal publication through the relevant DOI and the license). See: https://creativecommons.org/licenses/by-nc-nd/4.0/.

\section{References}

1. Selway JL, Harikumar PE, Chu A, et al. Genetic homogeneity of adult Langerhans cell histiocytosis lesions: Insights from BRAFV600Emutations in adult populations. Oncol Lett 2017;14:4449-54.

doi: 10.21037/jovs-2020-02

Cite this article as: Tripole KJS, Danguilan JLJ, Mendoza JM, Santiago RMC. VATS biopsy of an adult with pulmonary langerhans cell histiocytosis: case report. J Vis Surg 2021;7:21.
2. Vassallo R, Ryu JH, Schroeder DR, et al. Clinical outcomes of pulmonary Langerhans'-cell histiocytosis in adults. N Engl J Med 2002;346:484-90.

3. Goyal G, Young JR, Koster MJ, et al. The Mayo Clinic Histiocytosis Working Group Consensus Statement for the Diagnosis and Evaluation of Adult Patients With Histiocytic Neoplasms: Erdheim-Chester Disease, Langerhans Cell Histiocytosis, and Rosai-Dorfman Disease. Mayo Clin Proc 2019;94:2054-71.

4. Hansell DM, Bankier AA, MacMahon H, et al. Fleischner Society: glossary of terms for thoracic imaging. Radiology 2008;246:697-722.

5. Youkeles LH, Grizzanti JN, Liao Z, et al. Decreased tobacco-glycoprotein-induced lymphocyte proliferation in vitro in pulmonary eosinophilic granuloma. Am J Respir Crit Care Med 1995;151:145-50.

6. Tazi A, Soler P, Hance AJ. Adult pulmonary Langerhans' cell histiocytosis. Thorax 2000;55:405-16.

7. Lacronique J, Roth C, Battesti JP, et al. Chest radiological features of pulmonary histiocytosis X: a report based on 50 adult cases. Thorax 1982;37:104-9.

8. Moore AD, Godwin JD, Muller NL, et al. Pulmonary histiocytosis X: comparison of radiographic and CT findings. Radiology 1989;172:249-54.

9. Tazi A. Adult pulmonary Langerhans' cell histiocytosis. Eur Respir J 2006;27:1272-85.

10. Tazi A, Montcelly L, Bergeron A, et al. Relapsing nodular lesions in the course of adult pulmonary Langerhans cell histiocytosis. Am J Respir Crit Care Med 1998;157:2007-10.

11. Mogulkoc N, Veral A, Bishop PW, et al. Pulmonary Langerhans' cell histiocytosis: radiologic resolution following smoking cessation. Chest 1999;115:1452-5. 